\title{
Molecular design for recombinant adeno-associated virus (rAAV) vector production
}

\author{
Juan Jose Aponte-Ubillus ${ }^{1,2} \cdot$ Daniel Barajas $^{1} \cdot$ Joseph Peltier $^{1} \cdot$ Cameron Bardliving $^{2} \cdot$ Parviz Shamlou $^{2} \cdot$ Daniel Gold $^{1}$
}

Received: 11 September 2017 / Revised: 17 November 2017 / Accepted: 20 November 2017 / Published online: 4 December 2017

(C) The Author(s) 2017. This article is an open access publication

\begin{abstract}
Recombinant adeno-associated virus (rAAV) vectors are increasingly popular tools for gene therapy applications. Their nonpathogenic status, low inflammatory potential, availability of viral serotypes with different tissue tropisms, and prospective longlasting gene expression are important attributes that make rAAVs safe and efficient therapeutic options. Over the last three decades, several groups have engineered recombinant AAV-producing platforms, yielding high titers of transducing vector particles. Current specific productivity yields from different platforms range from $10^{3}$ to $10^{5}$ vector genomes (vg) per cell, and there is an ongoing effort to improve vector yields in order to satisfy high product demands required for clinical trials and future commercialization.

Crucial aspects of vector production include the molecular design of the rAAV-producing host cell line along with the design of AAV genes, promoters, and regulatory elements. Appropriately, configuring and balancing the expression of these elements not only contributes toward high productivity, it also improves process robustness and product quality. In this mini-review, the rational design of rAAV-producing expression systems is discussed, with special attention to molecular strategies that contribute to high-yielding, biomanufacturing-amenable rAAV production processes. Details on molecular optimization from four rAAV expression systems are covered: adenovirus, herpesvirus, and baculovirus complementation systems, as well as a recently explored yeast expression system.
\end{abstract}

Keywords Adeno-associated virus $\cdot$ Gene therapy $\cdot$ Bioprocessing $\cdot$ Vector production

\section{Introduction}

Recombinant adeno-associated viruses (rAAV) have gained increasing attention in the viral gene therapy field. A safe clinical profile, availability of viral serotypes with different tissue tropisms, and potential long-term gene expression are main advantages of rAAV as viral vector. To date, more than 100 gene therapy clinical trials have been conducted, tackling a variety of diseases such as lipoprotein lipase (LPL) deficiency, cystic fibrosis, and hemophilic disorders (Carter 2005;

Juan Jose Aponte-Ubillus

Juan.aponte@bmrn.com

1 Biomarin Pharmaceutical Inc., 105 Digital drive, Novato, CA 94949, USA

2 Keck Graduate Institute of Applied Life Sciences, 535 Watson drive, Claremont, CA 91711, USA
Bryant et al. 2013; Gene therapy clinical trials website: http://www.abedia.com/wiley/).

Production of rAAV vectors started approximately 32 years ago, after different groups demonstrated formation of genetically modified AAV viral particles capable of infecting and transducing mammalian cells (Tratschin et al. 1984; Hermonat and Muczycska 1984). From a clinical perspective, these findings raised the possibility for developing a new type of therapeutic DNA vector. From a biotechnology and bioprocessing perspective, this new biologic represented a unique market opportunity, assuming that biotech manufacturing capabilities could meet quantity and quality requirements. Subsequently, significant effort has been put toward the design of simple and efficient processes for rAAV production.

Three expression systems are currently used for industrial vector production: adenovirus (AdV), herpesvirus (HSV), and baculovirus (BV) complementation systems. Despite promising advances, there are several challenges associated with the manufacturing process. Complementation systems bring inherent complexity to the production process because rAAV 
formation requires an intricate interplay between virus and host genetic elements. This phenomenon has a direct effect on process robustness and understanding, as subtle variations on the number of biological or chemical inputs used in upstream bioprocessing can affect productivity. This problem is clearly seen in transfection-based protocols, where lot-to-lot yield can vary drastically based on the number and concentration of plasmids used, amount of transfection agent used, cell viability, and mode of operation (Wright 2009; Huang et al. 2013; van der Loo and Wright 2016). Another concern during vector production refers to the generation of product-related impurities. Some components used during cell culture readily copurify with rAAV or are difficult to remove without damaging the rAAV product, making purification challenging. Among them, collateral packaging of non-AAV DNA has raised concerns because of its potential clinical implications (Wright 2014). Finally, vector yield is one of the most limiting factors for potential commercial supply. Current specific productivity yields from different platforms range from $10^{3}$ to $10^{5}$ vector genomes (vg) per cell, and there is an ongoing effort to improve vector yields to satisfy high product demands (Clark 2002; Ayuso et al. 2010). Overall, the best molecular constructs are the ones where the nature of AAV genes, promoters, and regulatory elements contribute to a simple, economic process that generates safe, high-quality vectors.

In this mini-review, the rational design of rAAV-producing expression systems is discussed, with special attention to molecular strategies that contribute to high-yielding, biomanufacturing-amenable rAAV production processes. In addition, in-depth details of a new microbial system for rAAV vector production based on Saccharomyces cerevisiae are provided. The molecular configuration proposed by different groups and their potential implications in vector production processes are discussed. Other aspects of gene therapy vector bioprocessing such as cell line and inoculum scalability, transfection optimization, and media optimization are covered elsewhere (Negrete and Kotin 2008; Kotin 2011; Thomas et al. 2009; Clement and Grieger 2016; Robert et al. 2017).

\section{rAAV vector biology}

AAV is a non-enveloped, single-stranded DNA virus that belongs to the family Parvoviridae. The 4.7-kb genome contains two main open reading frames, Rep and Cap (Fig. 1a). Rep encodes four regulatory proteins (Rep78, Rep68, Rep52, and Rep40) that play important roles in replication and encapsidation of viral DNA. Cap encodes three capsid proteins (VP1, VP2, and VP3) and assembly-activating protein (AAP) that promotes capsid formation. The genome is flanked by inverted terminal repeats (ITRs) which contain Rep recognition sequences important for AAV DNA replication and packaging (Samulski and Muzycska 2014). As a Dependoparvovirus, AAV requires the aid of another virus to propagate in tissue culture. Adenovirus and herpes simplex virus have been traditionally used as AAV helper virus.

An AAV vector is a recombinant variant of the wild-type (wt) AAV virus, in which the natural coding and non-coding regions have been replaced by an expression cassette not bigger than $4.7 \mathrm{~kb}$. The vector genetic construct retains the lateral ITRs which are the only cis-acting elements required for replication and encapsidation of AAV DNA. With these modifications, rAAV becomes a replication-deficient entity, capable only of infecting cells and delivering DNA into their nuclei. As shown in Fig. 1b, vector production in culture requires Rep and Cap genes to be provided in a separate construct (Kotterman and Schaffer 2014). AAV genetic elements can be re-arranged in multiple constructs and then delivered into host cells via plasmid transfection or viral infection. Helper virus activities are also required for efficient vector production. They are provided by coinfection with helper virus stock or transfection with a plasmid containing "helper" genes.

\section{Molecular design of rAAV-producing expression systems}

\section{Adenovirus complementation system}

Early AAV-producing systems contained three components: a plasmid with the transgene of interest flanked by ITRs, Rep and Cap genes expressed from wild-type AAV or from a second plasmid, and AdV to provide helper functions (Tratschin et al. 1985). These systems showed positive AAV-like biological functionality (i.e., AAV DNA replication, formation of AAV full particles, DNA rescue, and replication after AdV coinfection) and served as a proof of concept for rAAV production. However, this process had limited potential for clinical use due to low yield and the presence of process-related impurities such as contaminating $\mathrm{AdV}$ and replicationcompetent (rc) AAV.

Subsequent approaches based exclusively on plasmid transfection removed the need for wild-type AdV coinfection and usually require transfection with two or three plasmids containing the vector sequence (ITR-transgene-ITR), Rep/ Cap genes, and helper virus auxiliary genes. Matsushita et al. (1998) evaluated different helper plasmid configurations in the search for the minimal set of genes required for AdVfree AAV vector production. Their best design included one plasmid with combined AAV vector and Rep/Cap genes and a second plasmid containing VA RNA, E4orf6, and E2A adenoviral genes. Because the HEK293 host cells already constitutively expressed the adenovirus proteins E1a and E1b, the full helper gene set included the five aforementioned proteins whose role on AAV production has been determined (Weitzman and Leiden 2011). This configuration tackled the initial problem of formation of replication-competent AAV 
a
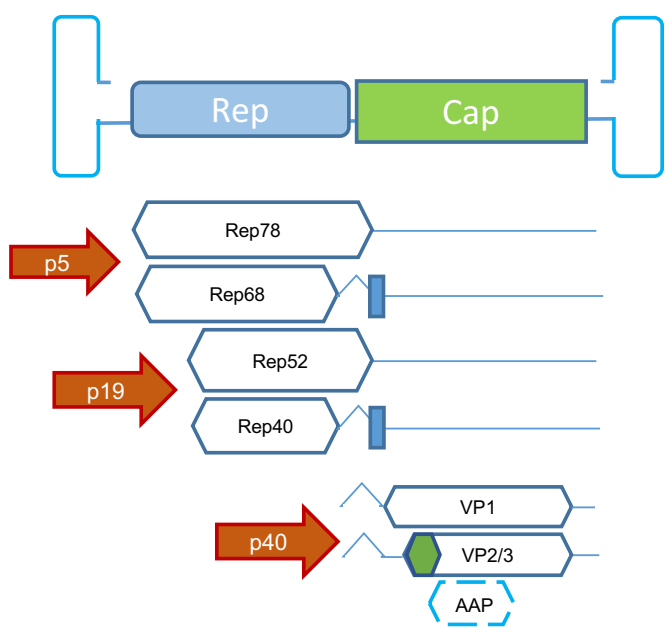

b

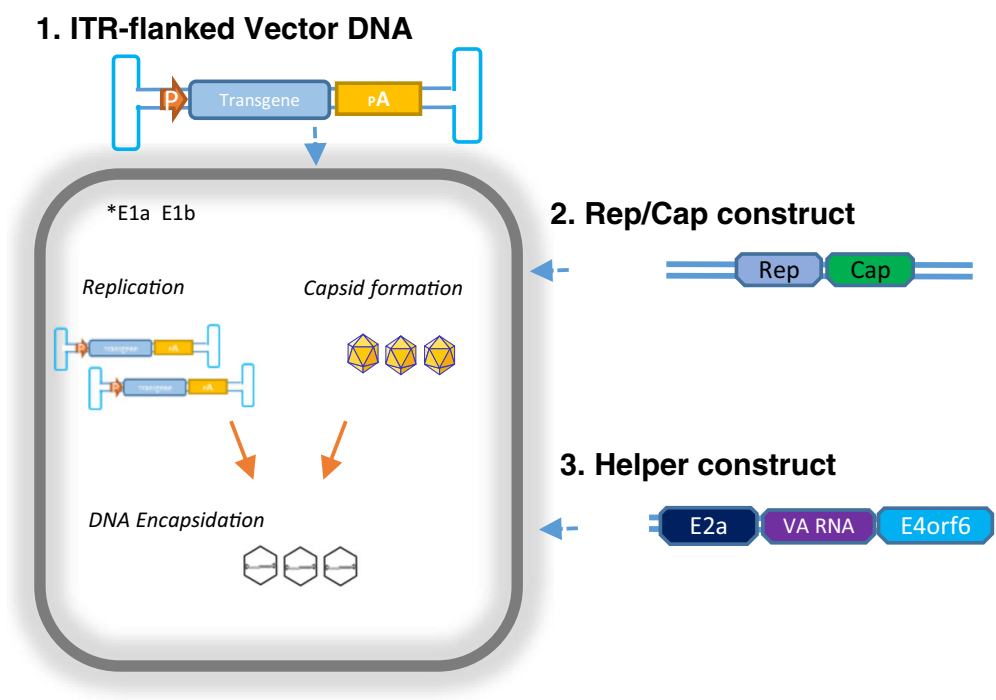

Fig. 1 Adeno-associated virus (AAV) vector biology. Wild-type AAV genome (a) contains Rep and Cap genes. Rep encodes four regulatory proteins that play important roles in replication and encapsidation of viral DNA, and their expression is controlled by $\mathrm{p} 5$ and $\mathrm{p} 19$ promoters. Cap encodes three capsid proteins and assembly-activating protein (AAP), regulated by 40 promoter. In an AAV vector (b), the wild-type AAV Rep and Cap genes have been replaced with the transgene of interest. Three components have to be delivered into the host cell line either by transfection or viral infection: vector AAV DNA containing the transgene

and removed the need for infectious adenovirus. In parallel, reduction of rc-AAV formation was also accomplished by altering homologous sequences present in both vector and helper plasmids (Allen et al. 1997). Subsequent efforts aimed at reducing process and product-related impurities have been reported (Fig. 2).

Despite design improvements, per cell productivity was lower than wild-type AAV viral yields (Clark 2002; of interest, Rep and Cap genes (also known as packaging construct), and helper genes from adenovirus. Rep 78 and 68 promote AAV DNA rescue and subsequent replication. Cap proteins are synthesized in the cytoplasm and are shuttled to the nucleus for assembly. AAP supports assembly and maturation of the AAV capsid (Samulski and Muzyczka 2014). Rep52 and 40 interact with single-stranded DNA and pre-formed capsids to promote viral DNA encapsidation by a mechanism not yet fully understood (Ling et al. 2015). P, promoter; pA, polyadenylation sequence

Samulski and Muzyczka 1999). Several observations on natural AAV production indicated that the higher particle per cell yields might be linked to (1) higher Rep and Cap gene copies per cell because of ITR-based DNA self-replication and (2) controlled expression of Rep78 levels has a positive impact on vector yield, and ameliorate Rep-mediated cytotoxicity which otherwise would impact cell viability (Schmidt et al. 2000; Xiao et al. 1998). Based on those premises, several groups
Fig. 2 rAAV production-related impurities and molecular strategies aimed for their reduction. Adapted from Wright (2014)
Process-related impurities

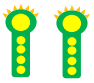

-Host and viral DNA

-Host and viral proteins

-Helper virus (i.e. AdV,HSV, BV)

-Replication-competent AAV

-Defective interfering viral particles

(DIPs)
Product-related impurities

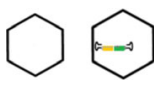

-Empty AAV capsids

-Full AAV capsids with foreign

DNA sequences

Molecular strategies to minimize the presence of impurities

-Development of helper virus plasmids to minimize the presence of AdV particles in harvested supernatant (Matsushita et al. 1998; Grimm et al. 1998)

-Remove homologous sequences present between AAV vector and helper plasmids to prevent rcAAV formation (Allen et al. 1997)

-Placement of Rep and Cap genes in opposite transcriptional orientation to prevent nonhomologous recombination-based rc-AAV formation (Allen et al. 1997)

-Use of an AAV vector oversized plasmid backbone $(\sim 6.9 \mathrm{~kb})$ to reduce the percentage of plasmid DNA insertion into formed AAV capsids (Hauck et al. 2008)

-Using a vaccinia virus-based carrier to deliver Rep and Cap genes in cytoplasm, reducing likelihood for homologous recombination events (Dong et al. 2013)

-Expression of AAV proteins from single Rep and Cap sequences prevented accumulation of DIPs, by reducing the amount of AAV Rep homologous sequences (Chen 2008) 
proposed variations of the initial design. Xiao et al. (1998) used a two-plasmid system for enhanced vector production. The packaging plasmid, $\mathrm{pXX} 2$, contained an unconventional initial codon ACG on the Rep gene to modulate its expression. In addition, this plasmid conformation included two $\mathrm{p} 5$ promoters (upstream of Rep and downstream of Cap) to improve $\mathrm{p} 5$ ' enhancer-like activity on the $\mathrm{p} 40$ promoter. The final yields obtained reached $10^{5}$ particles per cell, which exceeded the values obtained from Matsushita by nearly tenfold. Grimm et al. (1998) developed a pDG packaging plasmid, which combined Rep and Cap genes with AdV E2A, E4, and VA RNA helper genes. AAV p5 promoter was replaced by an MMTV-LTR promoter, which correlated to a reduction in Rep78 and increase in VP levels. Other molecular configurations were proposed by different groups, obtaining comparable vector yields (Allen et al. 2000; Collaco et al. 1999; Li and Samulski 2005; Table 1).

Such research efforts led to the adoption of the triple plasmid transfection system as one of the preferred methods for rAAV production. The standard configuration of this system provides the original Rep and Cap genes with their natural promoters ( $\mathrm{p} 5, \mathrm{p} 19$, and $\mathrm{p} 40$ ), but striped from other cisacting elements to reduce the probability of encapsidation. Under this configuration, one plasmid contains Rep and Cap genes, a second plasmid comprises the ITR-flanked transgene of interest, and a third plasmid provides helper genes (Fig. 3a). Recently, Emmerling et al. (2016) evaluated a new Rep/Cap split packaging plasmid system, in which the original Rep and Cap genes were segregated into two plasmids. In the first plasmid, the Rep gene was split into two expression cassettes, one for Rep68 and another for Rep52 and Rep40. A second plasmid contained the Cap expression cassette for expression of the three VP proteins and AAP from the natural p40 promoter. This study indicated that high yield correlated to an optimal Rep68/Rep52 expression ratio and enhanced Cap expression. Overall, a 12-fold increase in vector productivity (vg/cell) and a fivefold increase in transducing units/cell for this optimized plasmid transfection system were obtained, compared to the widely used pDG packaging system.

Although plasmid transfection methods offer simplicity and flexibility for basic research and early-stage rAAV production, these protocols have limited scalability and reproducibility for use in large-scale production. Alternatively, stable packaging and producer cell lines were designed. These two different systems contain Rep/Cap only or Rep/Cap plus vector constructs integrated into the cell genome, respectively. They all require the addition of Ad helper genes via plasmid transfection or virus infection, the latter being preferred to generate high yields (Chadeuf et al. 2000). This methodology improves cell culture process scalability and reduces the number of plasmids/virus required (Van der Loo and Wright 2016). Many variations of these stable cell lines have been designed (Gao et al. 1998; Gao et al. 2002; Clark et al.
1995; Qiao et al. 2002) giving vector genome titers ranging around $10^{4}-10^{6} \mathrm{vg} / \mathrm{cell}$.

\section{Herpesvirus complementation system}

Early studies performed by Weindler and Heilbronn (1991) confirmed that HSV coinfection allowed AAV propagation and that genes UL5/8/52 and DNA-binding protein gene UL29 were responsible for helper-like activities. The function of these HSV helper genes has also been determined (Weitzman and Leiden 2011). The HSV system became an alternative platform that could overcome production challenges identified in AdV-based systems, namely the complexity of large-scale transfection methods, as well as the presence of helper virus impurities. Early HSV plasmid designs used an HSV1 amplicon expressing AAV2 Rep and Cap proteins, plus wild-type HSV and a vector construct (Conway et al. 1997). This initial design was later improved by developing an ICP27-deficient HSV strain which expressed AAV Rep/Cap (Conway et al. 1999). This recombinant strain was incapable of replicating in culture, reducing the generation of impurities throughout the process. Replication-deficient rHSV Rep/Cap propagation was performed as a separate process, by cultivating the virus in ICP27-expressing Vero cells. Efficient production of rAAV on HEK293 cells was accomplished by transducing cells with rHSV Rep/Cap and transfecting an AAVGFP vector plasmid. Slightly better yields were observed when an HEK-derived, proviral cell line (GFP-92) was used. The use of replication-deficient rHSV shows no detectable levels of rc-AAV and low levels of viral helper particles in culture (Clement et al. 2009).

Current HSV-based design comprises two replicationdeficient HSV strains engineered to individually harbor Rep/ Cap and AAV vector sequences (Fig. 3b). This transfectionfree approach was initially reported by Hwang et al. (2003), who were able to improve vector yield 30 -fold relative to a transfection-based method after optimizing HSV multiplicity of infection (MOI) ratios (12 and 2 for rHSV/RepCap and rHSV/AAV-GFP viruses, respectively). Kang et al. (2009) expanded this rHSV-based, AAV production platform across multiple serotypes and transgenes with proven efficiency (higher than $1 \times 10^{5}$ particles/cell). Other groups adapted the infection process to suspension culture. Per cell productivity obtained after infecting suspension-adapted BHK cells ranged around $8 \times 10^{4}-2 \times 10^{5} \mathrm{vg} / \mathrm{cell}$ (Thomas et al. 2009; Knop et al. 2011). This modification allowed easier scale up and generated high yields. Current efforts are focused on improving viral inoculum growth and stability in culture.

\section{Insect cell—baculovirus expression system}

The baculovirus (BV) complementation system has become a reliable platform for expression of single heterologous 
Table 1 Reported rAAV vector yields on the articles cited in this mini-review

\begin{tabular}{|c|c|c|}
\hline Method/design & Vector yield & Reference \\
\hline \multicolumn{3}{|l|}{ AdV-based system } \\
\hline Ad-free, triple plasmid transfection & 120ETU/cell & $\begin{array}{l}\text { Matsushita et al. } \\
\text { (1998) }\end{array}$ \\
\hline Transient transfection, $\mathrm{pXX} 2$, unconventional start codon to modulate Rep expression & $\begin{array}{l}1.2 \times 10^{3} \text { ETU/cell } 9.4 \times 10^{5} \\
\quad \mathrm{vg} / \text { cell }\end{array}$ & Xiao et al. (1998) \\
\hline Rep/Cap Hela stable cell line + AdV & up to $36 \mathrm{IP} /$ cell & Clark et al. (1995) \\
\hline $\begin{array}{l}\text { Transient transfection, pSH3/pSH5 plasmids which combined AAV Rep, Cap, } \\
\text { and AdV-helper genes }\end{array}$ & $\begin{array}{l}1.3 \times 10^{4} \mathrm{vg} / \text { cell } \\
135 \mathrm{ETU} / \mathrm{cell}\end{array}$ & Collaco et al. (1999) \\
\hline Transient transfection with pDG plasmid, MMLV regulate Rep expression & $150 \mathrm{IP} /$ cell & Grimm et al. (1998) \\
\hline Transient transfection, Mtrep-CMVcap plasmid, E4orf6-only plasmid & $\begin{array}{l}10^{4} \mathrm{vg} / \mathrm{cell} \\
23 \mathrm{TU} / \mathrm{cell}\end{array}$ & Allen et al. (2000) \\
\hline Rep/Cap stable cell line A549 + AdV & $262 \mathrm{TU} / \mathrm{cell}$ & Gao et al. (2002) \\
\hline Rep/Cap stable cell line + AdV-Cre vector & $\begin{array}{l}1.3 \times 10^{5} \mathrm{vg} / \text { cell } \\
1.7 \times 10^{3} \mathrm{ETU} / \mathrm{cell}^{\mathrm{a}}\end{array}$ & Qiao et al. (2002) \\
\hline Self-replicating Rep/Cap helper construct & $2 \times 10^{9} \mathrm{IU} /$ well & $\begin{array}{l}\mathrm{Li} \text { and Samulski } \\
\quad(2005)\end{array}$ \\
\hline Transient transfection, Rep/Cap split system & $\begin{array}{l}2.6 \times 10^{5} \mathrm{vg} / \text { cell } \\
37.8 \mathrm{TU} / \text { cell }\end{array}$ & $\begin{array}{l}\text { Emmerling et al. } \\
\text { (2016) }\end{array}$ \\
\hline \multicolumn{3}{|l|}{ HSV-based system } \\
\hline Transient transfection, HSV-rc/d27 amplicon system & $480 \mathrm{vg} / \mathrm{cell}$ & Conway et al. (1997) \\
\hline Infection with rHSV-rc strain on AAV-GFP-integrated cell line & $480 \mathrm{ETU} / \mathrm{cell}$ & Conway et al. (1999) \\
\hline Infection with rHSV Rep/Cap and rHSV-GFP & $\begin{array}{l}1.5 \times 10^{5} \mathrm{vg} / \text { cell } \\
6 \times 10^{3} \mathrm{IP} / \text { cell }\end{array}$ & Hwang et al. (2003) \\
\hline Double infection with ICP27-deleted rHSV strains & $40 \mathrm{TU} / \mathrm{cell}$ & Booth et al. (2004) \\
\hline $\begin{array}{l}\text { Production of rAAV serotypes } 1,2 \text {, and } 9 \text {, by double infection with } \\
\text { ICP27-deleted rHSV strains }\end{array}$ & $\begin{array}{l}>1.3 \times 10^{5} \mathrm{vg} / \text { cell } \\
>9 \times 10^{3} \mathrm{IP} / \text { cell }\end{array}$ & Kang et al. (2009) \\
\hline $\begin{array}{l}\text { Production of rAAV serotypes } 1,2,5 \text { and } 8 \text {, by using suspension-adapted BHK } \\
\text { cells infected with rHSV strains }\end{array}$ & $\begin{array}{l}\text { up to } 1 \times 10^{5} \mathrm{vg} / \text { cell } \\
\text { up to } 1 \times 10^{4} \mathrm{IP} / \text { cell }\end{array}$ & Thomas et al. (2009) \\
\hline Suspension-adapted BHK cells infected with rHSV strains & $>5 \times 10^{4} \mathrm{vg} / \mathrm{cell}$ & Knop et al. (2011) \\
\hline \multicolumn{3}{|l|}{ BV-based system } \\
\hline Initial design, triple-BV system, Rep/Cap genes controlled by IE1/polh promoters & $\begin{array}{l}5 \times 10^{4} \mathrm{vg} / \mathrm{cell} \\
30 \mathrm{TU} / \mathrm{cell}\end{array}$ & Urabe et al. (2002) \\
\hline $\begin{array}{l}\text { Swapping of AAV genetic elements from different serotypes to improve } \\
\text { production of rAAV5 }\end{array}$ & $6 \times 10^{4} \mathrm{vg} /$ cell & Urabe et al. (2006) \\
\hline Intron-splicing mediated expression & $1 \times 10^{11} \mathrm{vg} / \mathrm{mL}$ & Chen (2008) \\
\hline $\begin{array}{l}\text { Stable cell line, integration of Rep/Cap sequences + hr2-0.9 homologous regions + RBE } \\
\text { sites }\end{array}$ & $>10^{5} \mathrm{vg} / \mathrm{cell}$ & Aslanidi et al. (2009) \\
\hline Stable cell line producing rAAV serotypes $1-12$ & up to $5 \times 10^{5} \mathrm{vg} /$ cell & Mietzsch et al. (2014) \\
\hline \multicolumn{3}{|l|}{ Yeast expression system } \\
\hline 4-plasmid system, individual expression cassettes regulated by Gal1/Gal10 promoters & $\sim 10^{8} \mathrm{vg} / \mathrm{mL}$ & Barajas et al. (2017) \\
\hline
\end{tabular}

$v g$ vector genomes, $E T U$ enhanced transducing unit, $T U$ transducing unit, $I P$ infectious particle, $I U$ infectious unit

${ }^{a}$ Assuming $5 \times 10^{6}$ cells per $10 \mathrm{~cm}$ plate were used for assay

proteins and multimeric particles. Using this method, recombinant viral strains usually derived from Autographa californica multinuclear polyhedrosis virus (AcMNPV) infect insect cells, hijacking the cellular machinery and expressing proteins encoded in the genome, including the foreign protein of interest. High per cell productivity yields are achieved because of BV's strong promoters. Insect cell lines such as $\mathrm{Sf} 9$ or Sf21 can grow in suspension and are easily adapted to scalable, stirred tank bioreactor-based processes (Merten et al.
2005). Evidence of human-like post-translational modification capacity and intracellular viral capsid assembly support its use as a production platform for complex surface antigens, virus-like particles (VLPs), and potentially fully assembled viral vectors (Van Oers et al. 2015; Fernandes et al. 2013).

Under these premises, several groups developed BV constructs that promoted AAV capsid formation, DNA replication, and subsequent packaging within Sf9 cells. Urabe et al. (2002) designed an rAAV2 production strategy 
Fig. 3 rAAV-producing systems: Production in adenovirus complementation systems (a) are traditionally performed as plasmid transfection processes, where AAV Rep/Cap genes, the ITR-flanked gene of interest (GOI), as well as AdV-helper genes are provided to a E1a/E1bcontaining HEK293 cell line. HSV complementation systems (b) use two recombinant herpes viral strains to provide AAV Rep/ Cap genes, GOI, and HSV-helper elements to a mammalian cell line such as BHK. Sf9-baculovirus expression systems $(\mathbf{c})$ require two recombinant $\mathrm{BV}$ viral strains to provide the AAV-producing capability to insect cells. AAV protein expression is controlled by $\mathrm{Sf} 9$ natural promoters. Yeastbased systems (d) are transformed with a set of extrachromosomal plasmids that contain six AAV expression cassettes and GOI. AAV protein expression is controlled by yeast natural promoters a

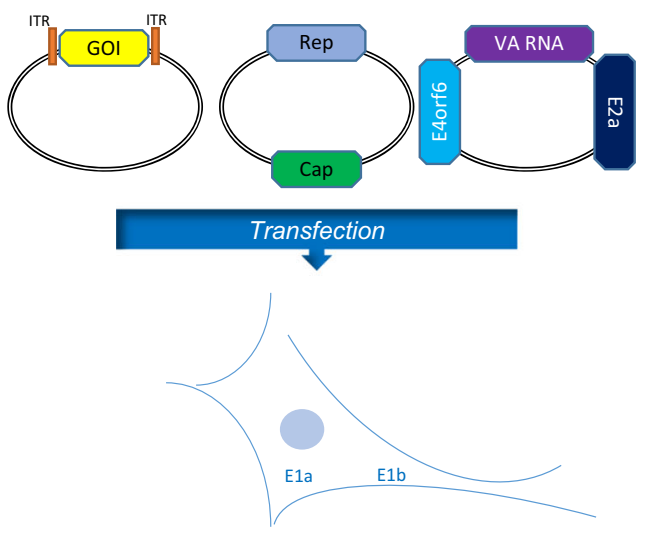

\section{C}

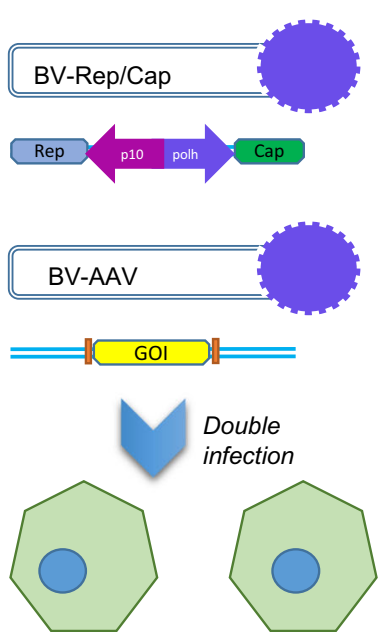

b

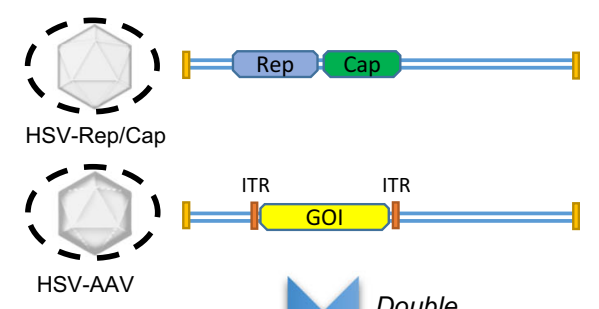

infection
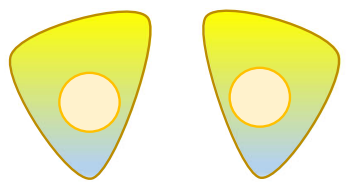

d

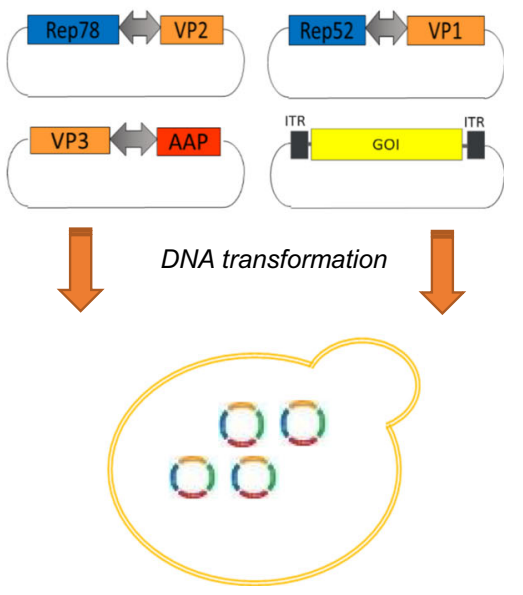

based on infection of Sf9 cells with three different recombinant BVs. The first BV carried Rep78 and Rep52 genes, the second carried the Cap gene, and the third carried the transgene flanked by ITRs. Preliminary experiments showed impaired Rep expression when AAV natural promoters were used; therefore, BV-specific promoters were adopted. Rep 78 and Rep52 expressions were expressed from two independent cassettes controlled by baculovirus immediate early $(\Delta \mathrm{IE} 1)$ and polyhedrin (polh) promoters, respectively. The three VP proteins were expressed from a single cassette controlled by the polh promoter, and the VP1 start codon was mutated to ACG to enable expression of the three VP proteins at the appropriate ratio, without the need of alternative splicing. Per cell productivity with this system achieved $5 \times 10^{4} \mathrm{vg} /$ cell. The final product resembled HEK293-produced AAV vectors in its physical and biological properties. The same author later developed a BV infection process for production of rAAV5 that achieved considerable yield ( $\sim$ fourfold) and infectivity improvements by swapping in serotype 1 Rep52 for the serotype 5 analog and the N-terminal portion of serotype 2 VP1 for the analogous portion from serotype 5 (Urabe et al. 2006). Chen (2008) further modified the system to allow expression of multiple proteins from single Rep and Cap coding sequences. Polh promoters were placed within intron sequences to drive expression of Rep and Cap short transcripts, allowing the production of Rep52, VP2, AAP, and VP3 proteins. Rep78 and VP1 proteins were translated from longer transcripts after splicing of the internal polh promoter sequence. Under this concept, Rep78/52 and VP1/2/3 expression was accomplished by infection with either one or two BVs. Yields of $10^{14} \mathrm{vg} / \mathrm{L}$ were reached with the two-BV and three-BV proposed systems. Alternatively, Smith et al. (2009) were able to express Rep genes from a single mRNA species based on an mRNA leaky scanning mechanism, in which several AUG codons found in the Rep 78 initial sequence (including the start codon) were mutated to suboptimal triplets, thus allowing translation of Rep52 by the ribosome. This concept was applied for both Rep and Cap, and the generated sequences were cloned in opposite transcriptional orientation and consolidated into one Rep/Cap BV.

Overall, the new two-BV design (Fig. 3c) supported process robustness and scalable production of infectious rAAV by 
reducing the number of required BV viruses and additionally increased virus stability. The latter aspect becomes relevant when using replication-competent baculovirus for vector production, as defective-interfering viral particles (DIPs) can emerge during culture. DIPs are variants that gain a competitive advantage against complete baculovirus by deleting subsets of genes. Outgrowth of DIPs correlates to loss of transgene and reduced rAAV productivity in insect cells. Strategies to prevent DIP formation during rAAV production include BV inoculum optimization at minimum multiplicity of infection (MOI) and molecular changes in the BV that reduce the number of homologous Rep sequences (Cecchini et al. 2008).

The generation of stable insect cell lines for production of recombinant AAV vectors has also been explored. Aslanidi et al. (2009) developed an inducible system that required infection with a single BV strain. The Rep and Cap sequences, controlled by baculovirus promoters, were integrated within the $\mathrm{Sf} 9$ genome, and subsequent $\mathrm{AAV}$ gene amplification was triggered as a result of infection with a BV carrying an ITRflanked transgene. The addition of a Rep binding element (RBE) upstream of Rep and Cap likely promoted feedforward amplification of AAV gene expression. Overall, vector yields were improved by tenfold in comparison to the three-BV process. Mietzsch et al. (2014) further expanded Aslanidi's design and generated a production platform for rAAV serotypes 1-12 called OneBac. Rep genes from AAV2, 4, or 12 were used in combination with the Cap genes to generate yield improvements similar to Aslanidi (up to $5 \times$ $10^{5} \mathrm{vg} / \mathrm{cell}$ ), but now for all serotypes. Mietzsch, however, noticed a decrease in VP1 levels and vector infectivity for rAAV5. Further improvements of this Sf9-infected stable production system (Mietzsch et al. 2015) based on the intronsplicing approach proposed by Chen (2008) led to a recovery of rAAV5 infectivity. Additionally, the authors were able to reduce collateral packaging of baculovirus genomic DNA by removing the previously integrated RBE signal.

The insect cell BV expression system is one of the most promising platforms for recombinant AAV production. The Sf9 system's per cell productivity and volumetric productivity are among the highest documented to date $\left(>10^{5} \mathrm{vg} / \mathrm{cell} ;\right.$ $10^{11} \mathrm{vg} / \mathrm{mL}$ ) (Samulski and Muzyczka 2014). Efforts are currently underway to further improve cell-specific productivity, BV stability, and process scalability.

\section{AAV-producing yeast system}

Saccharomyces cerevisiae is a unicellular, eukaryotic organism commonly used in research and technology. Baker's yeast's features include simple growth requirements, wellunderstood genetics, and post-translational protein processing comparable to complex eukaryotic systems excepting subtle differences in N-linked glycosylation patterns (Nielsen 2013). These characteristics make Saccharomyces suitable not only as a model system for eukaryotic cell biology studies, but also as a heterologous protein expression system for biotechnology applications. Saccharomyces' value has been explored in the pharmaceutical industry. Recombinant strains capable of producing therapeutic proteins, antigenic proteins, and virus-like particles (VLPs) have been generated. Its proven record of heterologous viral protein expression, evidence of assembled capsid production, and evidence of virus replication of some entities such as Parvovirus suggested the possibility of generating full AAV viral particles in this organism (Kim and Kim 2016; Bill 2015; Zhao and Frazer 2002a; Zhao and Frazer 2002b).

Recent studies investigated rAAV generation in yeast. Backovic et al. (2012) utilized various plasmid constructs to demonstrate capsid protein expression and AAV capsid assembly in Saccharomyces. Their initial design placed the Rep and Cap genes under the control of their natural promoters along with an intron placed upstream of the VP1 initiation sequence. This design allowed the recovery of VP3 protein only. A second design with the Cap gene under a Gall promoter and a Kozak region upstream of VP1 facilitated expression of VP1. Cotransformation with the previously mentioned plasmids and optimized gene induction led to successful expression of VP1 and VP3 at a ratio comparable to theory. Transmission electron microscopy studies confirmed capsid morphology of the purified product. Moreover, the same group demonstrated AAV single-stranded genome replication dependent on Rep expression and the presence of ITRs. DNA analysis of replicated sequences led the authors to suggest that AAV DNA replication process in yeast appear to be dissimilar from AAV canonical replication (Cervelli et al. 2011).

Barajas et al. (2017) demonstrated production of fully assembled, infectious AAV particles in S. cerevisiae. The system was based on four plasmids containing individual expression cassettes for two Rep proteins (Rep78 and Rep52), three VP capsid proteins, and the assembly-activating protein (AAP) (Fig. 3d). Unlike previous efforts, protein expression from the six expression cassettes was controlled by yeast-specific, galactose-inducible GAL promoters of different strengths, and codon optimization was required on Rep and AAP sequences. Southern blot analysis demonstrated formation of AAV DNA monomeric forms, and Western blot analysis of purified capsids showed detectable levels of the three VP capsids. Further examination confirmed transgene presence and infectious capacity of the purified material. The authors reported rAAV2 full particle titer yield that ranges around $10^{8} \mathrm{vg} / \mathrm{mL}$. This four-plasmid system design aligns with other similarly proposed plasmid configurations (Thakur 2002; Snyder 2011), and altogether, these studies constitute the proof-of-concept of rAAV production in a microbial system. The reported results not only demonstrate the potential utility of the yeast system as a tool to investigate AAV biology; this new concept 
raises the possibility of potentially developing an alternative, cost-effective, highly scalable platform for rAAV production at large manufacturing scale. However, low vector yields and poor DNA encapsidation rates limit its application. Certain functionalities like those provided by helper viruses and host factors in other systems may be suboptimal in yeast and would need to be supplemented for high yield rAAV production. More investigations are needed to understand the benefits and limitations of this system that, although promising, is still far from becoming an efficient rAAV production platform.

\section{Final remarks}

The molecular design of rAAV-producing expression systems plays a critical role not only in per cell vector productivity, but also in process robustness and elimination of process and product-related impurities. Each production system has advantages and disadvantages when adopted in pre-clinical or clinical manufacturing environments. AdV complementation systems based on triple plasmid transfection process are commonly adopted in lab settings because of their simple rAAV production workflow, flexibility to switch production to different AAV serotypes, and proven productivity and product quality. Scaling up this system, however, brings challenges associated to cell adaptation to suspension culture, plasmid generation, and lot-lo-lot variability in transfection efficiency. The HSV complementation system based on the use of rHSVs overcomes scale-up limitations regarding to cell culture scaleup and process variability, while maintaining high productivity at large scale. One of the main challenges of this system relies on the viral inoculum stability and propagation. Production of AAV vectors in the Sf9/BV complementation system has proven to be very efficacious, and several studies demonstrated the suitability of this system for large-scale vector production. However, like other systems based on viral infection, special attention needs to be focused on the viral inoculum stability and generation. Additionally, more studies need to be performed to fully characterize quality attributes of Sf9-based vector material (Wang et al. 2011).

All rAAV expression systems have three fundamental commonalities: (1) successful delivery and amplification of the necessary genetic material into the host cell line, (2) finetuning of Rep-Cap expression levels, and (3) modification of the cellular milieu to a more "AAV-friendly" environmentsomething that has only recently begun to be investigated. The use of non-native hosts for rAAV production brings also the need to optimize critical variables such as timing and strength of expression of AAV components.

Besides molecular optimization of AAV genes, some research has focused on identifying limitations imposed by the host cells on rAAV production or the negative effects caused by rAAV on the cells. Satkunanathan et al. (2014) identified Y- box binding protein (YB1) as an inhibitory protein of rAAV production. They postulated this protein could interfere with viral DNA encapsidation by competitive binding for recognition sequences. Experimental silencing of this gene translated into a significant increase in rAAV2 titer relative to control condition. Reid et al. (2017) hypothesized producer cells could experience cytotoxicity driven by rAAV transgene overexpression. mRNA silencing studies on different transgenes resulted in yield improvement up to 22-fold relative to control. Future research efforts in multiple directions will hopefully translate to highly productive vector expression systems.

Acknowledgments The authors would like to thank BioMarin Pharmaceutical Inc. for financial support for JJAU graduate studies, as well as for covering publication costs associated to this manuscript.

\section{Compliance with ethical standards}

Conflict of interest The authors declare that they have no conflict of interest.

Ethical approval This article does not contain any studies with human participants or animals performed by any of the authors.

Open Access This article is distributed under the terms of the Creative Commons Attribution 4.0 International License (http:// creativecommons.org/licenses/by/4.0/), which permits unrestricted use, distribution, and reproduction in any medium, provided you give appropriate credit to the original author(s) and the source, provide a link to the Creative Commons license, and indicate if changes were made.

\section{References}

Allen JM, Debelak DJ, Reynolds TC, Miller AD (1997) Identification and elimination of replication-competent adeno-associated virus (AAV) that can arise by nonhomologous recombination during AAV vector production. J Virol 71(9):6816-6822

Allen JM, Halbert CL, Miller AD (2000) Improved adeno-associated virus vector production with transfection of a single helper adenovirus gene, E4orf6. Mol Ther 1(1):88-95. https://doi.org/10.1006/mthe.1999.0010

Aslanidi G, Lamb K, Zolotukhin S (2009) An inducible system for highly efficient production of recombinant adeno-associated virus (rAAV) vectors in insect Sf9 cells. Proc Natl Acad Sci U S A 106(13):50595064. https://doi.org/10.1073/pnas.0810614106

Ayuso E, Mingozzi F, Bosch F (2010) Production, purification and characterization of adeno-associated vectors. Curr Gene Ther 10(6):423436. https://doi.org/10.2174/156652310793797685

Backovic A, Cervelli T, Salvetti A, Zentilin L, Giacca M, Galli A (2012) Capsid protein expression and adeno-associated virus like particles assembly in Saccharomyces cerevisiae. Microb Cell Factories 11(1): 124. https://doi.org/10.1186/1475-2859-11-124

Barajas D, Aponte-Ubillus JJ, Akeefe H, Cinek T, Peltier J, Gold D (2017) Generation of infectious recombinant Adeno-associated virus in Saccharomyces cerevisiae. PLoS One 12(3):e173010. https://doi.org/10.1371/journal.pone. 0173010

Bill RM (2015) Recombinant protein subunit vaccine synthesis in microbes: a role for yeast? J Pharm Pharmacol 67(3):319-328. https:// doi.org/10.1111/jphp. 12353 
Booth MJ, Mistry A, Li X, Thrasher A, Coffin RS (2004) Transfectionfree and scalable recombinant AAV vector production using $\mathrm{HSV} /$ AAV hybrids. Gene Ther 11(10):829-837. https://doi.org/10.1038/ sj.gt.3302226

Bryant LM, Christopher DM, Giles AR, Hinderer C, Rodriguez JL, Smith JB, Traxler EA, Tycko J, Wojno AP, Wilson JM (2013) Lessons learned from the clinical development and market authorization of Glybera. Hum Gene Ther Clin Dev 24(2):55-64. https://doi.org/10. 1089/humc.2013.087

Carter BJ (2005) Adeno-associated virus vectors in clinical trials. Hum Gene Ther 16(5):541-550. https://doi.org/10.1089/hum.2005.16. 541

Cecchini S, Negrete A, Kotin RM (2008) Toward exascale production of recombinant adeno-associated virus for gene transfer applications. Gene Ther 15(11):823-830. https://doi.org/10.1038/gt.2008.61

Cervelli T, Backovic A, Galli A (2011) Formation of AAV single stranded DNA genome from a circular plasmid in Saccharomyces cerevisiae. PLoS One 6(8):e23474. https://doi.org/10.1371/journal.pone. 0023474

Chadeuf G, Favre D, Tessier J, Provost N, Nony P, Kleinschmidt J, Moullier P, Salvetti A (2000) Efficient recombinant adenoassociated virus production by a stable rep-cap HeLa cell line correlates with adenovirus-induced amplification of the integrated repcap genome. J Gene Med 2(4):260-268. https://doi.org/10.1002/ 1521-2254(200007/08)2:4<260::AID-JGM111>3.0.CO;2-8

Chen H (2008) Intron splicing-mediated expression of AAV Rep and Cap genes and production of AAV vectors in insect cells. Mol Ther 16(5):924-930. https://doi.org/10.1038/mt.2008.35

Clark KR (2002) Recent advances in recombinant adeno-associated virus vector production. Kidney Int 61(1):S9-15. https://doi.org/10.1046/ j.1523-1755.2002.0610s1009.x

Clark KR, Voulgaropoulou F, Fraley DM, Johnson PR (1995) Cell lines for the production of recombinant adeno-associated virus. Hum Gene Ther 6(10):1329-1341. https://doi.org/10.1089/hum.1995.6. $10-1329$

Clément N, Grieger JC (2016) Manufacturing of recombinant adenoassociated viral vectors for clinical trials. Mol Ther Methods Clin Dev 3:16002. https://doi.org/10.1038/mtm.2016.2

Clément N, Knop DR, Byrne BJ (2009) Large-scale adeno-associated viral vector production using a herpesvirus-based system enables manufacturing for clinical studies. Hum Gene Ther 20(8):796806. https://doi.org/10.1089/hum.2009.094

Collaco RF, Cao X, Trempe JP (1999) A helper virus-free packaging system for recombinant adeno-associated virus vectors. Gene 238(2):397-405. https://doi.org/10.1016/S0378-1119(99)00347-9

Conway JE, Zolotukhin S, Muzyczka N, Hayward GS, Byrne BJ (1997) Recombinant adeno-associated virus type 2 replication and packaging is entirely supported by a herpes simplex virus type 1 amplicon expressing Rep and cap. J Virol 71(11):8780-8789

Conway JE, Rhys CM, Zolotukhin I, Zolotukhin S, Muzyczka N, Hayward GS, Byrne BJ (1999) High-titer recombinant adenoassociated virus production utilizing a recombinant herpes simplex virus type I vector expressing AAV-2 Rep and Cap. Gene Ther 6(6): 986-993. https://doi.org/10.1038/sj.gt.3300937

Dong B, Moore AR, Dai J, Roberts S, Chu K, Kapranov P, Moss B, Xiao W (2013) A concept of eliminating nonhomologous recombination for scalable and safe AAV vector generation for human gene therapy. Nucleic Acids Res 41(13):6609-6617. https://doi.org/10.1093/ nar/gkt404

Emmerling VV, Pegel A, Milian EG, Venereo-Sanchez A, Kunz M, Wegele J, Kamen AA, Kochanek S, Hoerer M (2016) Rational plasmid design and bioprocess optimization to enhance recombinant adeno-associated virus (AAV) productivity in mammalian cells. Biotechnol J 11(2):290-297. https://doi.org/10.1002/biot. 201500176
Fernandes F, Teixeira AP, Carinhas N, Carrondo MJ, Alves PM (2013) Insect cells as a production platform of complex virus-like particles. Expert Rev Vaccines 12(2):225-236. https://doi.org/10.1586/erv.12.153

Gao GP, Qu G, Faust LZ, Engdahl RK, Xiao W, Hughes JV, Zoltick PW, Wilson JM (1998) High-titer adeno-associated viral vectors from a Rep/Cap cell line and hybrid shuttle virus. Hum Gene Ther 9(16): 2353-2362. https://doi.org/10.1089/hum.1998.9.16-2353

Gao G, Lu F, Sanmiguel JC, Tran PT, Abbas Z, Lynd KS, Marsh J, Spinner NB, Wilson JM (2002) Rep/Cap gene amplification and high-yield production of AAV in an A549 cell line expressing Rep/Cap. Mol Ther 5(5):644-649. https://doi.org/10.1006/mthe. 2001.0591

Gene Therapy Clinical Trials Worldwide (2017). Wiley online library. http://www.abedia.com/wiley/. Accessed Sep 2017

Grimm D, Kern A, Rittner K, Kleinschmidt JA (1998) Novel tools for production and purification of recombinant adeno associated virus vectors. Hum Gene Ther 9(18):2745-2760. https://doi.org/10.1089/ hum.1998.9.18-2745

Hauck B, Murphy SL, Smith PH, Qu G, Liu X, Zelenaia O, Mingozzi F, Sommer JM, High KA, Wright JF (2009) Undetectable transcription of cap in a clinical AAV vector: implications for preformed capsid in immune responses. Mol Ther 17(1):144-152. https://doi.org/10. 1038/mt.2008.227

Hermonat PL, Muzyczka N (1984) Use of adeno-associated virus as a mammalian DNA cloning vector: transduction of neomycin resistance into mammalian tissue culture cells. Proc Natl Acad Sci U S A 81(20):6466-6470. https://doi.org/10.1073/pnas.81.20.6466

Huang X, Hartley A-V, Yin Y, Herskowitz JH, Lah JJ, Ressler KJ (2013) AAV2 production with optimized N/P ratio and PEI-mediated transfection results in low toxicity and high titer for in vitro and in vivo applications. J Virol Methods 193(2):270-277. https://doi.org/10. 1016/j.jviromet.2013.06.008

Hwang K, Mandell T, Kintner H, Zolotukhin S, Snyder RO, Byrne BJ (2003) High titer recombinant adeno-associated virus production using replication deficient herpes simplex viruses type I. Mol Ther 7(5):S14-S15. https://doi.org/10.1016/S1525-0016(16)40477-6

Kang W, Wang L, Harrell H, Liu J, Thomas DL, Mayfield TL, Scotti MM, Ye GJ, Veres G, Knop DR (2009) An efficient rHSV-based complementation system for the production of multiple rAAV vector serotypes. Gene Ther 16(2):229-239. https://doi.org/10.1038/gt. 2008.158

Kim HJ, Kim H-J (2016) Yeast as an expression system for producing virus-like particles: what factors do we need to consider? Lett Appl Microbiol 64(2):111-123. https://doi.org/10.1111/lam.12695

Knop DR, Thomas DL, Butts C (2011) SFM rHSV-based production of rAAV vectors in suspension BHK cells. Mol Ther 19:S227. https:// doi.org/10.1016/S1525-0016(16)37166-0

Kotin RM (2011) Large-scale recombinant adeno-associated virus production. Hu Mol Genet 20(R1):R2-R6. https://doi.org/10.1093/ hmg/ddr141

Kotterman MA, Schaffer DV (2014) Engineering adeno-associated viruses for clinical gene therapy. Nat Rev Genet 15(7):445-451. https:// doi.org/10.1038/nrg3742

Li C, Samulski RJ (2005) Serotype-specific replicating AAV helper constructs increase recombinant AAV type 2 vector production. Virology 335(1):10-21. https://doi.org/10.1016/j.virol.2005.02.008

Ling C, Wang Y, Lu Y, Wang L, Jayandharan GR, Aslanidi GV, Li B, Cheng B, Ma W, Lentz T, Ling C, Xiao X, Samulski RJ, Muzyczka N, Srivastava A (2015) The adeno-associated virus genome packaging puzzle. J Mol Genet Med 09(03). https://doi.org/10.4172/ 1747-0862.1000175

van der Loo JCM, Wright JF (2016) Progress and challenges in viral vector manufacturing. Hum Mol Genet 25(R1):R42-R52. https:// doi.org/10.1093/hmg/ddv451

Matsushita T, Elliger S, Elliger C, Podsakoff G, Villarreal L, Kurtzman GJ, Iwaki Y, Colosi P (1998) Adeno-associated virus vectors can be 
efficiently produced without helper virus. Gene Ther 5(7):938-945. https://doi.org/10.1038/sj.gt.3300680

Merten O-W, Gény-Fiamma C, Douar AM (2005) Current issues in adeno-associated viral vector production. Gene Ther 12(S1):S51S61. https://doi.org/10.1038/sj.gt.3302615

Mietzsch M, Grasse S, Zurawski C, Weger S, Bennett A, AgbandjeMcKenna M, Muzyczka N, Zolotukhin S, Heilbronn R (2014) OneBac: platform for scalable and high-titer production of adenoassociated virus serotype 1-12 vectors for gene therapy. Hum Gene Ther 25(3):212-222. https://doi.org/10.1089/hum.2013.184

Mietzsch M, Casteleyn V, Weger S, Zolotukhin S, Heilbronn R (2015) OneBac 2.0: Sf9 cell lines for production of AAV5 vectors with enhanced infectivity and minimal encapsidation of foreign DNA. Hum Gene Ther 26(10):688-697. https://doi.org/10.1089/hum.2015.050

Negrete A, Kotin RM (2008) Strategies for manufacturing recombinant adeno-associated virus vectors for gene therapy applications exploiting baculovirus technology. Brief Funct Genomic Proteomic 7(4):303-311. https://doi.org/10.1093/bfgp/eln034

Nielsen J (2013) Production of biopharmaceutical proteins by yeast. Bioengineered 4(4):207-211. https://doi.org/10.4161/bioe.22856

van Oers MM, Pijlman GP, Vlak JM (2015) Thirty years of baculovirusinsect cell protein expression: from dark horse to mainstream technology. J Gen Virol 96(1):6-23. https://doi.org/10.1099/vir.0. 067108-0

Qiao C, Wang B, Zhu X, Li J, Xiao X (2002) A novel gene expression control system and its use in stable, high-titer 293 cell-based adenoassociated virus packaging cell lines. J Virol 76(24):13015-13027. https://doi.org/10.1128/JVI.76.24.13015-13027.2002

Reid CA, Boye SL, Hauswirth WW, Lipinski DM (2017) miRNAmediated post-transcriptional silencing of transgenes leads to increased adeno-associated viral vector yield and targeting specificity. Gene Ther. doi: https://doi.org/10.1038/gt.2017.50

Robert M-A, Chahal PS, Audy A, Kamen A, Gilbert R, Gaillet B (2017) Manufacturing of recombinant adeno-associated viruses using mammalian expression platforms. Biotechnol J 12(3):1600193. https://doi.org/10.1002/biot.201600193

Samulski RJ, Muzyczka N (1999) Adeno-associated viral vectors. In: Friedmann $\mathrm{T}$ (ed) The development of gene therapy. Cold Spring Harbor, New York, pp 131-172

Samulski RJ, Muzyczka N (2014) AAV-mediated gene therapy for research and therapeutic purposes. Annu Rev Virol 1(1):427-451. https://doi.org/10.1146/annurev-virology-031413-085355

Satkunanathan S, Wheeler J, Thorpe R, Zhao Y (2014) Establishment of a novel cell line for the enhanced production of recombinant adenoassociated virus vectors for gene therapy. Hum Gene Ther 25(11): 929-941. https://doi.org/10.1089/hum.2014.041

Schmidt M, Afione S, Kotin RM (2000) Adeno-associated virus type 2 Rep78 induces apoptosis through Caspase activation independently of p53. J Virol 74(20):9441-9450. https://doi.org/10.1128/JVI.74. 20.9441-9450.2000

Smith RH, Levy JR, Kotin RM (2009) A simplified baculovirus-AAV expression vector system coupled with one-step affinity purification yields high-titer rAAV stocks from insect cells. Mol Ther 17(11): 1888-1896. https://doi.org/10.1038/mt.2009.128
Snyder RO (2011) Production of recombinant AAV virions. US patent 7, $927,585 \mathrm{~B} 2$

Thakur SS (2002) Production of recombinant adeno-associated viral vectors in yeast. Dissertation. University of Florida. http://ufdc.ufl.edu/ UFE0044702/00001

Thomas DL, Wang L, Niamke J, Liu J, Kang W, Scotti MM, Ye G-J, Veres G, Knop DR (2009) Scalable recombinant adeno-associated virus production using recombinant herpes simplex virus type 1 coinfection of suspension-adapted mammalian cells. Hum Gene Ther 20(8):861-870. https://doi.org/10.1089/hum.2009.004

Tratschin JD, West MH, Sandbank T, Carter BJ (1984) A human parvovirus, adeno-associated virus, as a eucaryotic vector: transient expression and encapsidation of the procaryotic gene for chloramphenicol acetyltransferase. Mol Cell Biol 4(10):2072-2081. https://doi. org/10.1128/MCB.4.10.2072

Tratschin JD, Miller IL, Smith MG, Carter BJ (1985) Adeno-associated virus vector for high-frequency integration, expression, and rescue of genes in mammalian cells. Mol Cell Biol 5(11):3251-3260. https://doi.org/10.1128/MCB.5.11.3251

Urabe M, Ding C, Kotin RM (2002) Insect cells as a factory to produce adeno-associated virus type 2 vectors. Hum Gene Ther 13(16): 1935-1943. https://doi.org/10.1089/10430340260355347

Urabe M, Nakakura T, Xin K-Q, Obara Y, Mizukami H, Kume A, Kotin RM, Ozawa K (2006) Scalable generation of high-titer recombinant adeno-associated virus type 5 in insect cells. J Virol 80(4):1874 1885. https://doi.org/10.1128/JVI.80.4.1874-1885.2006

Wang L, Blouin V, Brument N, Bello-Roufai M, Francois A (2011) Production and purification of recombinant adeno-associated vectors. Methods Mol Biol 807:361-404. https://doi.org/10.1007/9781-61779-370-7 16

Weindler FW, Heilbronn R (1991) A subset of herpes simplex virus replication genes provides helper functions for productive adenoassociated virus replication. J Virol 65(5):2476-2483

Weitzman MD, Linden RM (2011) Adeno-associated virus biology. Methods Mol Biol 807:1-23. https://doi.org/10.1007/978-1-61779370-7 1 1

Wright JF (2009) Transient transfection methods for clinical adenoassociated viral vector production. Hum Gene Ther 20(7):698706. https://doi.org/10.1089/hum.2009.064

Wright JF (2014) Product-related impurities in clinical-grade recombinant AAV vectors: characterization and risk assessment. Biomedicine 2(1):80-97. https://doi.org/10.3390/ biomedicines 2010080

Xiao X, Li J, Samulski RJ (1998) Production of high-titer recombinant adeno-associated virus vectors in the absence of helper adenovirus. J Virol 72(3):2224-2232

Zhao K-N, Frazer IH (2002a) Replication of bovine papillomavirus type 1 (BPV-1) DNA in Saccharomyces cerevisiae following infection with BPV-1 virions. J Virol 76(7):3359-3364. https://doi.org/10. 1128/JVI.76.7.3359-3364.2002

Zhao K-N, Frazer IH (2002b) Saccharomyces cerevisiae is permissive for replication of bovine papillomavirus type 1. J Virol 76(23):1226512273. https://doi.org/10.1128/JVI.76.23.12265-12273.2002 